\title{
Different Molecular Forms of Invertase in the slime Variant of Neurospora crassa: Comparison with the Wild-type Strain
}

\author{
By MANUEL CASANOVA, JOSE P. MARTINEZ, M. LUISA GIL, \\ RAFAEL SENTANDREU* AND JOSE RUIZ-HERRERA \\ Departament de Microbiologia, Facultat de Farmacia, Universitat de Vàlencia, Avgda. Blasco \\ Ibañez 13, 46010-Vàlencia, Spain
}

(Received 27 October 1986; revised 6 March 1987)

\begin{abstract}
Invertase synthesis, regulation and secretion in the wall-less slime variant of Neurospora crassa was studied. Unlike the wild-type, synthesis of the enzyme was not repressed by glucose. This effect was not related to the os mutation harboured by the slime strain, nor to the phenotypic absence of a cell wall. Three molecular forms of extracellular invertase, which varied in size, were detected in the slime strain. These forms were interconvertible, with the equilibrium in favour of the larger form. Polypeptide analysis of the three separated forms revealed that all contained the same glycoprotein with an $M_{\mathrm{r}}$ of 97000 . This was completely deglycosylated by treatment with endo- $\beta$ - $N$-acetylglucosaminidase $\mathrm{H}$ (Endo $\mathrm{H}$ ) to a polypeptide with an $M_{\mathrm{r}}$ of 72000. It was concluded that the three interconvertible forms correspond to the monomeric, dimeric and tetrameric states of the enzyme. Three similar forms of invertase, albeit of slightly different electrophoretic mobility, were found in cell-free extracts, cell walls and spent culture medium of the wild-type strain. After Endo $\mathrm{H}$ treatment, analysis showed that these forms contained a polypeptide that was equally reactive against anti-Saccharomyces cerevisiae antibodies, and had the same $M_{\mathrm{r}}$, as the polypeptide produced by the slime strain.
\end{abstract}

\section{INTRODUCTION}

The slime strain of Neurospora crassa lacks a defined cell wall because of its incapacity to synthesize the structural polysaccharides chitin and glucan (Leal-Morales \& Ruiz-Herrera, 1985). This strain contains normal or higher amounts of chitin synthase (Selitrennikoff, 1979; Bartnicki-Garcia et al., 1984; Leal-Morales \& Ruiz-Herrera, 1985) compared to the wild-type strain, but has no detectable glucan synthase activity (Leal-Morales \& Ruiz-Herrera, 1985). It has been hypothesized that the normal mechanisms for delivery to the cell surface or for activation of both transglycosidases are inefficient in this strain (Leal-Morales \& Ruiz-Herrera, 1985). On the other hand, secretion of invertase (Bigger et al., 1972) and several other extracellular glycoproteins (J. P. Martinez, M. Casanova, M. L. Gil, H. Rico, R. Sentandreu \& J. Ruiz-Herrera, unpublished) seems to be unaffected in this strain. These observations suggest that synthesis and transport of structural polysaccharides and extracellular glycoproteins occur independently from each other.

To gain information on how these routes of macromolecule externalization operate, the study of invertase secretion in the slime strain appears attractive. A considerable body of information on invertase regulation, structure and gene control exists for Saccharomyces cerevisiae (Gascon et al., 1968; Perlman \& Halvorson, 1981; Carlson \& Botstein, 1982), but data for the N. crassa system are very scant and relate to the walled wild-type strain only, in which the enzyme is localized, as in $S$. cerevisiae, in the periplasmic space (Metzenberg, 1963a, $b ; 1964$; Sargent \&

Abbreviation: PMSF, phenylmethylsulphonyl fluoride. 
Woodward, 1969; Meachum et al., 1971; Bigger \& Braymer, 1975). However, nothing is known about the invertase produced by the wall-less slime strain.

In this work we studied the regulation of invertase secretion in the slime strain and compared the results to invertase secretion in wild-type $N$. crassa.

\section{METHODS}

Strains, culture media and growth conditions. $N$. crassa wild-type strain FGSC 988 (St Lawrence 74-OR8-1 a), the os-1 B-135 mutant FGSC 951 and the wall-less slime strain FGSC 1118 were used throughout this work. Vogel's $\mathrm{N}$ medium (Vogel, 1964) supplemented with different sugars ( $2 \%$, w/v, final concentration), nutrient broth $(0.75 \%)$, and yeast extract $(0.75 \%)(\mathrm{pH} 5.8)$ was normally used to grow the wild-type strain and the os- 1 mutant. For growth of the slime strain and os-I protoplasts, this medium was supplemented with $1 \mathrm{M}$-sorbitol. This is a modification of Scarborough's 'diet' medium (Scarborough, 1975), and is described in the text as SDM medium. The wild-type strain and $o s-1$ mutant were maintained on $1.5 \%(\mathrm{w} / \mathrm{v})$ agar slants of Vogel's $\mathrm{N}$ medium supplemented with $2 \%$ $(\mathrm{w} / \mathrm{v})$ sucrose and $0.06 \mu \mathrm{g}$ biotin $\mathrm{ml}^{-1}$. The slime strain was maintained on $1.5 \%$ agar slants of SDM medium, and subcultured every $10-15 \mathrm{~d}$.

Strains were propagated in liquid media essentially as described by Leal-Morales \& Ruiz-Herrera (1985). For short incubation periods in order to measure invertase secretion, cells were harvested by centrifugation, washed once with $1.2 \mathrm{M}$-sorbitol, and transferred to the appropriate fresh medium.

The $o s-1$ mutant was propagated as a protoplast population following a procedure modified from that of Selitrennikoff et al. (1981). An Erlenmeyer flask $(250 \mathrm{ml})$ containing $10 \mathrm{ml}$ filter-sterilized Vogel's $\mathrm{N}$ medium supplemented with $1.5 \%$ sucrose, $10 \%(\mathrm{w} / \mathrm{v})$ sorbose, $0.02 \mathrm{mg}^{2}$ biotin $\mathrm{ml}^{-1}, 0.4 \mathrm{mg}$ arginine $\mathrm{ml}^{-1}$ and $0.4 \mathrm{mg}$ nikkomycin ml-1 was inoculated with $10^{5}$ microconidia $\mathrm{ml}^{-1}$, and incubated at $37^{\circ} \mathrm{C}$ with gentle shaking. After $48 \mathrm{~h}$ incubation the culture was filtered through glasswool to remove mycelium. Fresh medium $(10 \mathrm{ml})$ was then added to the filtered culture which was incubated again at $37^{\circ} \mathrm{C}$ for $48 \mathrm{~h}$. This step was repeated several times until a homogeneous population of $o s-1$ protoplasts was obtained.

Preparation of cell samples and cell-free extracts. Wild-type and os- 1 mutant germlings or young mycelia were harvested by centrifugation at $1000 \mathrm{~g}$ for $10 \mathrm{~min}$, or by filtration through Whatman no. 41 paper, and washed with the appropriate buffer. Mycelia were transferred to Duran bottles, mixed with glass beads, and shaken in a MSK cell homogenizer (Braun) for $60 \mathrm{~s}$ while the vessel was cooled with a stream of liquid $\mathrm{CO}_{2}$. Cell walls from the wildtype strain were sedimented from cell-free extracts at $1000 \mathrm{~g}$ for $10 \mathrm{~min}$, thoroughly washed by centrifugation with water, and freeze-dried. slime and os- 1 protoplasts were harvested by centrifugation at $1000 \mathrm{~g}$ for $10 \mathrm{~min}$, washed twice with a solution of $1.2 \mathrm{M}$-sorbitol, and lysed by resuspension in the appropriate enzyme assay buffer without osmotic stabilizer.

Determination of enzyme activities. Invertase was determined by the procedure of Gascon \& Lampen (1968). Before assaying invertase activity in samples from the different spent culture medium, the samples were dialysed for $48 \mathrm{~h}$ at $4{ }^{\circ} \mathrm{C}$ against $4 \times 2110 \mathrm{~mm}$-sodium acetate buffer, $\mathrm{pH} 4 \cdot 9$. One unit of invertase activity is the amount of enzyme that released $1.0 \mu \mathrm{mol}$ glucose $\mathrm{min}^{-1}$. Invertase activity in polyacrylamide gels was detected according to Gabriel \& Wang (1969).

Separation of oligomeric forms of invertase. Chilled absolute ethanol was added to spent culture medium containing invertase activity to give a final ethanol concentration of $75 \%(\mathrm{v} / \mathrm{v})$. The mixture was allowed to stand at $4{ }^{\circ} \mathrm{C}$ for $48-72 \mathrm{~h}$. The material precipitated by ethanol was recovered by centrifugation $(27000 \mathrm{~g}, 30 \mathrm{~min})$, dried under a stream of nitrogen, and resuspended in $50 \mathrm{~mm}$-ammonium acetate buffer, $\mathrm{pH} 4.9$. The resuspension was clarified by centrifugation at $3000 \mathrm{~g}$ for $10-15 \mathrm{~min}$. The resulting supernatant was passed through a Sephadex G-50 column $(1.6 \times 13 \mathrm{~cm}$, gel bed volume $25 \mathrm{ml})$ equilibrated with $50 \mathrm{~mm}$-ammonium acetate buffer, $\mathrm{pH} 4 \cdot 9$. The void volume that eluted from the column and contained the invertase activity was recovered and freeze-dried. The lyophilized sample was resuspended in ammonium acetate buffer, applied to a Sephadex G-100 column $(1.6 \times 70 \mathrm{~cm}, 140 \mathrm{ml}$ gel bed volume), and eluted with the same buffer. Fractions $(1.5 \mathrm{ml})$ were collected, and those containing invertase activity were pooled (see below) and freeze-dried. Dried material was resuspended in small volumes of buffer solution, and subjected to non-denaturing preparative gel electrophoresis (see below). To recover the different invertase forms separated after electrophoresis, $1 \mathrm{~cm}$ longitudinal strips were cut out from both sides of the gel; one strip was stained for invertase activity whereas the other one was stained with Coomassie blue. The remainder of the gel was frozen and transverse sections corresponding to the invertase activity as revealed by the stained strips were cut out, crushed, and extracted for $24 \mathrm{~h}$ at $4{ }^{\circ} \mathrm{C}$ in $50 \mathrm{mM}$-ammonium acetate buffer. The crushed gel was sedimented by centrifugation, re-extracted as above, centrifuged again, and the supernatants obtained after both extractions were pooled and freeze-dried. The different oligomeric forms of invertase recovered by this procedure were submitted to further analysis by gel electrophoresis under denaturing or non-denaturing conditions, before or after endo- $\beta$ - $N$-acetylglucosaminidase $\mathrm{H}$ (Endo $\mathrm{H}$ ) treatment. 
Cell-wall-bound invertase from the wild-type strain. Cell-wall-bound invertase was extracted from purified cell walls by digestion of the wall glucan network with Zymolyase $20 \mathrm{~T}$ [50 $\mu \mathrm{g}$ Zymolyase $20 \mathrm{~T}$ (mg dry wt cell wall) ${ }^{-1}$ ], in a final volume of $1 \mathrm{ml}$ distilled water containing $4 \mathrm{~mm}$-phenylmethylsulphonyl fluoride (PMSF), for $12 \mathrm{~h}$ at $28^{\circ} \mathrm{C}$ with gentle agitation. The digested cell wall residue was removed by centrifugation, and the supernatant obtained was freeze-dried. The lyophilized material was resuspended in $50 \mathrm{~mm}$-ammonium acetate buffer, $\mathrm{pH} 4.9$, and subjected to electrophoretic analysis either under non-denaturing or denaturing conditions.

Treatment with Endo $\mathrm{H}$. Lyophilized invertase samples were treated (at $28^{\circ} \mathrm{C}$ with gentle agitation for $48 \mathrm{~h}$ ) with Endo $\mathrm{H}(0.01$ units per 10 units of invertase activity, corresponding to about $25-50 \mu \mathrm{g}$ invertase protein) in $0 \cdot 1 \mathrm{ml}$ reaction volumes containing $150 \mathrm{~mm}$-sodium citrate, $\mathrm{pH} 5 \cdot 5,1 \mathrm{mM}-\mathrm{PMSF}, 10 \mu \mathrm{M}$-pepstatin A and $5 \mathrm{~mm}$-sodium azide. The reaction products were analysed either by denaturing or non-denaturing gel electrophoresis as described below. In all cases, the samples applied to gels contained about 2 units of invertase activity $(5-10 \mu \mathrm{g}$ invertase protein).

Polyacrylamide gel electrophoresis $(P A G E)$ under non-denaturing conditions. Endo-H-treated or untreated invertase samples ( 2 vols) were diluted with electrophoresis sample buffer $(1 \mathrm{vol} .: 35 \%, \mathrm{v} / \mathrm{v}$, glycerol, $7 \%$, w/v, SDS and $0.0035 \%$ bromophenol blue as tracking dye in $0.5 \mathrm{M}-\mathrm{Tris} / \mathrm{HCl}, \mathrm{pH} 6 \cdot 8$ ), and loaded onto $7.5-15 \%(\mathrm{w} / \mathrm{v})$ linear acrylamide gradient slabs (acrylamide : bisacrylamide ratio $30: 0.2$ ) made up in $0.37 \mathrm{M}-\mathrm{Tris} / \mathrm{HCl}$ buffer, pH 8.8, plus $0 \cdot 1 \%$ SDS. The running buffer system used was $25 \mathrm{~mm}$-Tris/192 mM-glycine, pH $8 \cdot 3$, containing $0 \cdot 1 \%$ SDS. Electrophoresis was done at a constant current $\left(30 \mathrm{~mA}\right.$ per slab) at $4{ }^{\circ} \mathrm{C}$ until the tracking dye front was $0.5 \mathrm{~cm}$ from the bottom edge of the gel. For analytical purposes $1.5 \mathrm{~mm}$ thick gels were used, whereas preparative gels were $3 \mathrm{~mm}$ thick.

Gel electrophoresis under denaturing conditions (SDS-PAGE) and blotting. Proteins were separated using the discontinuous buffer system of Laemmli (1970) in $7.5-15 \%$ linear acrylamide gradient gels (acrylamide : bisacrylamide ratio $30: 0 \cdot 2$ ). Samples were treated with the same sample buffer system as described above but containing $14 \%(\mathrm{v} / \mathrm{v})$ 2-mercaptoethanol (sample : solubilizing solution, $2: 1, \mathrm{v} / \mathrm{v}$ ) and heated for $5 \mathrm{~min}$ in a boiling water bath before being loaded onto the gels. For estimation of $M_{\mathrm{r}}$, under denaturing or non-denaturing conditions, gels were calibrated by running in parallel the following $M_{\mathrm{r}}$ markers: myosin (205000), $\beta$-galactosidase (116000), phosphorylase b (97000), bovine albumin (66000), ovalbumin (45000) and carbonic anhydrase (29000). In all cases, the marker proteins were denatured as above.

Electrophoretic transfer to Trans-Blot nitrocellulose paper was as described by Burnette (1981), except that the transfer buffer used was $25 \mathrm{~mm}$-Tris/192 mM-glycine, pH 8.3, plus $20 \%(\mathrm{v} / \mathrm{v})$ methanol, and electrophoretic transfer was done at $6-8 \mathrm{~V} \mathrm{~cm}^{-1}$ for $15-17 \mathrm{~h}$ at $4{ }^{\circ} \mathrm{C}$ in a BioRad Trans-Blot cell using an LKB 2197 power supply. Concanavalin A staining of nitrocellulose blots was done according to Hawkes (1982) with the modifications of Millette \& Scott (1984). Immunochemical detection of proteins on blots was done by following the protocol described in the BioRad Immun-Blot (GAR-HRP) assay kit based on the procedures of Towbin et al. (1979) and Burnette (1981), using the specific antibody at a final $1: 500$ dilution in $10 \mathrm{~mm}$-Tris/ $\mathrm{HCl}, \mathrm{pH} \mathrm{7.4,} \mathrm{plus} 1 \%$ bovine serum albumin, $0.9 \% \mathrm{NaCl}$ and $0.05 \%$ Tween 20 .

Miscellaneous. Protein was estimated by the Lowry procedure. Anti-S. cerevisiae invertase antibodies, obtained as described by Esmon et al. (1981), were kindly provided by S. Mormeneo and J. Zueco of this Department. Gel electrophoresis and blotting reagents were from Bio-Rad. SDS-PAGE and $M_{\mathrm{r}}$ markers were from Sigma. Gel filtration media (Sephadex G-50 and G-100) were supplied by Pharmacia. Endo H and Zymolyase 20T were from Miles Laboratories. Nikkomycin was kindly provided by Bayer. Culture media compounds were purchased from Difco. All other chemicals and reagents were obtained from Sigma or Merck.

\section{RESULTS}

\section{Invertase secretion by the slime strain of $N$. crassa}

Determination of invertase in the medium after growth of the slime strain revealed the presence of high levels of the enzyme. Cells grown for $48 \mathrm{~h}$ in SDM hypertonic medium with glucose were transferred to fresh medium containing either no sugar, glycerol or raffinose (a trisaccharide formed by elongation of sucrose with a galactose residue through a glycosidic bond). Secretion of invertase took place immediately with similar kinetics independently of the carbon source. After $6 \mathrm{~h}$ the extracellular enzyme levels were about 6-fold higher than those associated with the intact cells, which remained constant throughout this time (Fig. 1). Cycloheximide $\left(100 \mu \mathrm{g} \mathrm{ml}^{-1}\right)$ completely blocked enzyme secretion, thus demonstrating that secreted enzyme is synthesized de novo. In the presence of tunicamycin $\left(15 \mu \mathrm{g} \mathrm{ml}^{-1}\right)$ the levels of active enzyme in the medium were reduced by $95 \%$. This observation suggests that glycosylation is necessary for secretion of active invertase. 


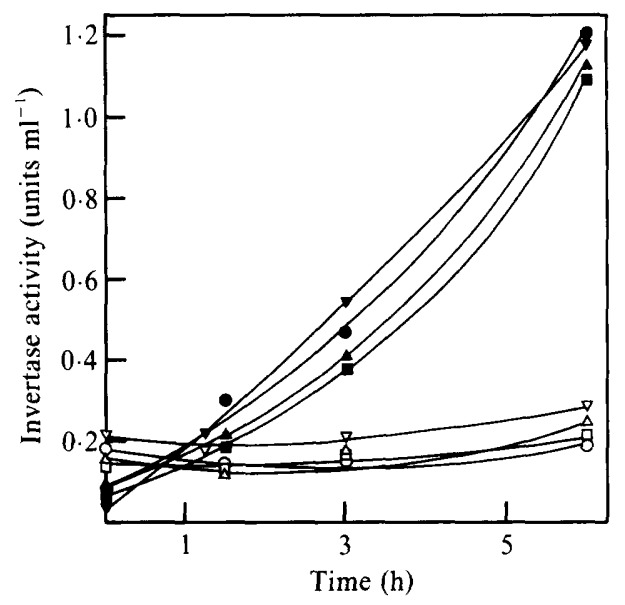

Fig. 1. Secretion of invertase by the slime strain of $N$. crassa. Cells grown for $48 \mathrm{~h}$ in glucose-containing SDM medium were transferred to fresh SDM medium containing no $\operatorname{sugar}(0,0), 2 \%$ glucose $(\nabla, \nabla)$, $2 \%$ glycerol $(\square, \square)$ or $2 \%$ raffinose $(\triangle, \Delta)$. Open symbols correspond to invertase activity detected in cell extracts, whereas closed symbols correspond to enzyme activity in the growth medium.

Table 1. Catabolite repression of invertase biosynthesis in the wild-type and os-1 mutant of N. crassa

Spores $\left(10^{6} \mathrm{ml}^{-1}\right)$ were inoculated into SDM (see Methods). Germlings were harvested by centrifugation, and washed and resuspended in $50 \mathrm{~mm}$-sodium acetate buffer, $\mathrm{pH} \mathrm{4.9}$. Cell growth is expressed as mg protein per $50 \mathrm{ml}$ medium. Invertase was measured in whole cells and is expressed as units (mg protein) $)^{-1}$.

$\begin{array}{lcccccc}\begin{array}{c}\text { Sugar } \\ \text { added to } \\ \text { medium }\end{array} & \overbrace{\begin{array}{c}\text { Cell } \\ \text { growth }\end{array}}^{\text {Invertase }} & \overbrace{\begin{array}{c}\text { Cell } \\ \text { growth }\end{array}}^{\text {Wild-type }} & \overbrace{\begin{array}{c}\text { Cell } \\ \text { growth }\end{array}}^{\text {Invertase }} \\ \text { None } & 5.72 & 0.843 & 22.6 & 2.225 & 2.05 & 0.324 \\ \text { Glucose }(2 \%) & 8.78 & 0.047 & 145.0 & 0.070 & 16.40 & 0.007\end{array}$

Regulation of invertase secretion in several strains of $N$. crassa

Synthesis of the large form of invertase (extracellular) is subject to catabolite repression in $S$. cerevisiae (Carlson \& Botstein, 1982). In the presence of glucose almost no enzyme is secreted. The results reported above showed that glucose had no inhibitory effect on the secretion of the enzyme in the slime strain of $N$. crassa (Fig. 1), indicating no catabolite repression.

We determined whether lack of catabolite repression was specific for the slime strain or a general phenomenon in other $N$. crassa strains. Wild-type conidia were germinated in liquid media containing different sugars, and extracellular invertase was measured. The results (Table 1) showed that invertase biosynthesis was repressed by glucose.

The $N$. crassa os 1 mutant is a strain harbouring one of the mutations present in the slime strain (Emerson, 1963). Invertase secretion by this strain was also repressed by glucose either in the absence or in the presence of the concentration of $\mathrm{NaCl}$ that allowed limited cell growth and phenotypic expression of osmotic sensitivity (Table 1).

To determine whether lack of catabolite repression in the slime strain was somehow related to the absence of the cell wall, the $o s-1$ mutant was grown as a protoplast population as described in Methods. When these protoplasts were transferred to SDM medium with or without glucose, secretion of invertase was shown to be subject to catabolite repression (Table 2). 
Table 2. Effect of glucose on invertase secretion by growing protoplasts of $N$. crassa os-1

Protoplasts of the $o s-1$ mutant, obtained as described in Methods, were harvested, and washed with $1.2 \mathrm{M}$-sorbitol. Samples of the protoplast suspension (about $10 \mathrm{mg}$ cell protein) were transferred to SDM medium containing $10 \%(\mathrm{w} / \mathrm{v})$ sorbose instead of sorbitol, and with or without glucose. At the indicated times, $10 \mathrm{ml}$ samples were withdrawn. Cells were separated from the medium by centrifugation, washed twice with $1.2 \mathrm{M}$-sorbitol, and resuspended in $50 \mathrm{~mm}$ sodium acetate buffer, $\mathrm{pH} 4.9$, plus $2 \%$ (v/v) Triton X-100. Invertase was measured in the cell extracts and in the dialysed spent medium (see Methods). Original invertase activity (time zero) was 0.006 units $\mathrm{ml}^{-1}$ in the cells and 0.002 units $\mathrm{ml}^{-1}$ in the medium.

\begin{tabular}{lccc}
$\begin{array}{c}\text { Sugar } \\
\text { added }\end{array}$ & $\begin{array}{c}\text { Incubation } \\
\text { time }(\mathrm{h})\end{array}$ & $\overbrace{\text { Cells }}^{\text {Invertase (units } \mathrm{ml}^{-1} \text { ) }}$ & Culture medium \\
None & 3 & $0 \cdot 032$ & 0.253 \\
\multirow{2}{*}{ Glucose $(2 \%)$} & 7 & $0 \cdot 102$ & $1 \cdot 173$ \\
& 3 & $0 \cdot 006$ & 0.004 \\
& 7 & 0.007 & 0.005
\end{tabular}

Secretion of different molecular forms of invertase by the slime strain

Gel filtration in a Sephadex G-100 column of the spent culture media revealed that invertase eluted as a broad ill-defined peak, with maximum activity in the void volume (not shown), thus suggesting that the enzyme was microheterogeneous.

In a further experiment the spent medium was subjected to gel filtration in a Sephadex G-50 column, and the void volume obtained passed through a column of Sephadex G-100; the material eluted from the latter column was combined into four pools (Fig. 2, A, B, C and D). Analysis of these pools by non-denaturing PAGE resulted in the separation of invertase into three forms with estimated $M_{\mathrm{r}}$ values of 76000,132000 and 235000 (Fig. $2 b$ ). The larger form dissociated into the other forms on subsequent electrophoresis under non-denaturing conditions (not shown).

\section{Different molecular forms of invertase in the wild-type strain}

About $28 \%$ of the cell-bound invertase remained firmly attached to the cell-wall fraction of the wild-type strain. Only a minor part of this invertase could be extracted with neutral detergents or with urea. However, the enzyme was completely released by treatment with Zymolyase. Extraction of invertase after digestion of walls with chitinase has also been reported (Meachum \& Braymer, 1969; Sargent \& Woodward, 1969; Chung \& Trevithick, 1970). Analysis of the released invertase by non-denaturing PAGE showed mainly two molecular forms with about the same apparent $M_{\mathrm{r}}$ (as revealed by their relative electrophoretic mobility) as forms I and II of the enzyme secreted by the slime strain (Fig. 3, lane A). Similar analysis of the invertase which, in low amounts, is normally present in the growth medium of young germlings of the fungus, also revealed the presence of two forms of the enzyme; however, these always exhibited lower electrophoretic mobilities than the corresponding forms extracted from the cell wall (Fig. 3, lane B).

\section{Molecular structure of $N$. crassa invertase}

The three molecular forms of invertase secreted by the slime strain are glycoprotein in nature, since treatment with Endo $H$ decreased their $M_{\mathrm{r}}$ values proportionally (Fig. 4). In order to determine the $M_{\mathrm{r}}$ values, the nature of the polysaccharide fraction, and the polypeptide composition of the different forms of invertase, they were separated as described in Methods. Staining of the non-denaturing preparative gels with Coomassie blue showed the presence of a single band corresponding to invertase form I, although invertase form III, and especially form II, were contaminated with other polypeptides (not shown). SDS-PAGE of the three isolated invertase forms revealed the presence of the same polypeptide before $\left(M_{\mathrm{r}} 97000\right)$ and after $\left(M_{\mathrm{r}}\right.$ 72000) Endo H treatment (Fig. 5, lanes A-F) (the lower $M_{\mathrm{r}}$ polypeptides present in the tracks corresponding to invertase forms II and III come from contaminating proteins). 


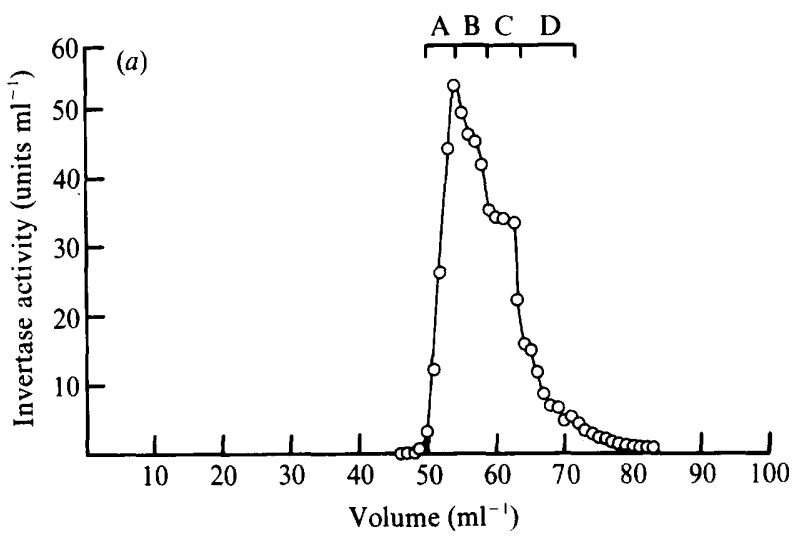

(b)

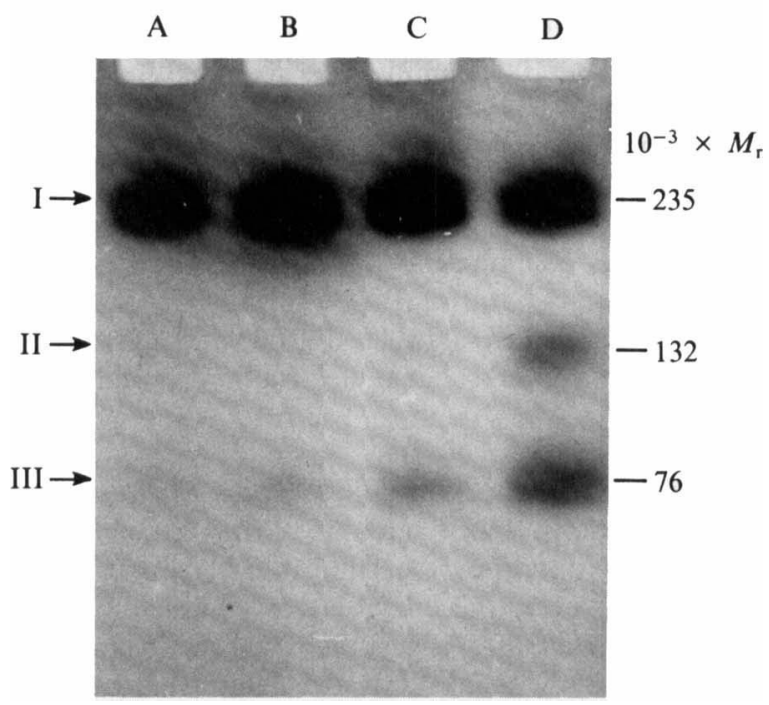

Fig. 2. Chromatographic behaviour of invertase forms secreted into the medium by slime cells. (a) Ethanol-precipitated culture medium was subjected to chromatography on a Sephadex G-100 column. (b) Fractions eluted from the column were pooled, freeze-dried, subjected to gel electrophoresis under non-denaturing conditions, and stained for invertase activity: lane A, fractions eluted from $50-54 \mathrm{ml}$; lane B, 55-58 ml; lane C, 59-63 ml; lane D, 64-72 ml. The different oligomeric forms (I, II, III) of invertase detected in the gel are indicated.

Treatment of the different invertase forms from the slime strain with Endo $\mathrm{H}$ left a polypeptide which did not react with Concanavalin A after blotting to nitrocellulose sheets (Fig. $6 a$, lane B). This observation indicates that treatment with Endo $\mathrm{H}$ completely removed the carbohydrate moiety of the molecule. Both glycosylated and deglycosylated polypeptides reacted with antibodies raised against $S$. cerevisiae invertase (Fig. $6 a$, lanes $\mathrm{C}$ and D). The $M_{\mathrm{r}}$ of the glycosylated polypeptide was calculated to be 97000 (Fig. 5, lane A); that of the deglycosylated polypeptide was 72000 (Fig. 5, lane B).

Anti-S. cerevisiae invertase antibodies were used to detect the invertase forms from wild-type $N$. crassa in nitrocellulose blots after SDS-PAGE. Invertase forms obtained from the culture medium and the periplasmic space (not shown), and that released from the cell walls by digestion with Zymolyase, all gave the same polypeptide after Endo $\mathrm{H}$ digestion, with an $\boldsymbol{M}_{\mathrm{r}}$ identical to that of the polypeptide from the invertase forms secreted by the slime strain (Fig. $6 b$, 
A

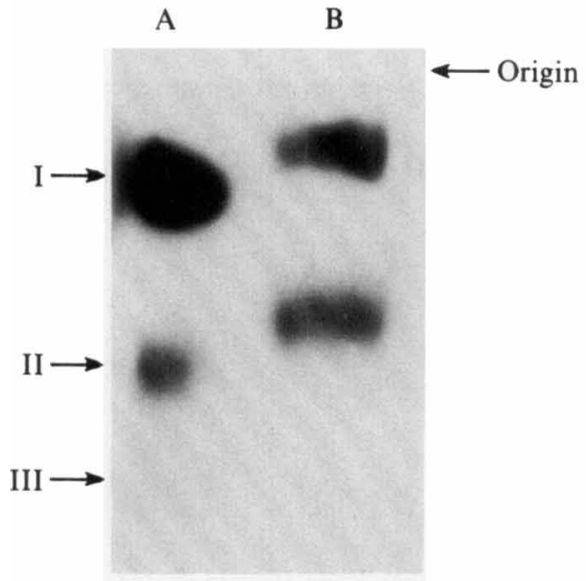

Fig. 3

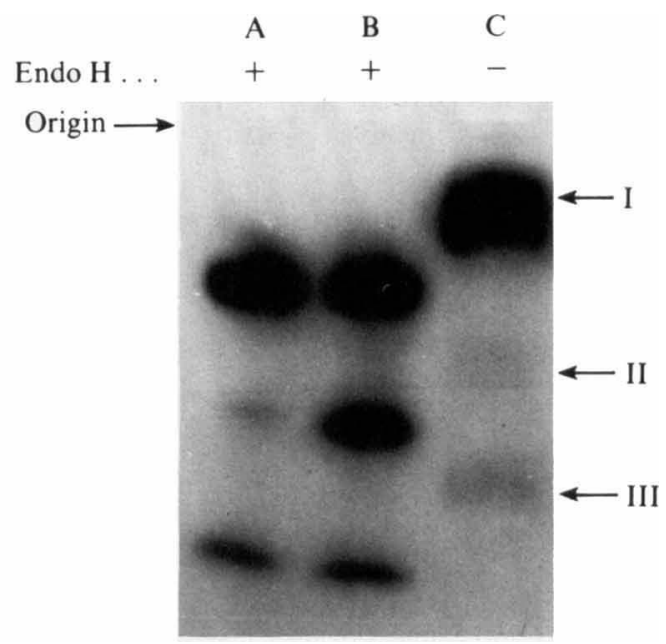

Fig. 4

Fig. 3. Invertase forms present in the cell walls (lane A) and the growth medium (lane B) of wild-type $N$. crassa. Separation was achieved by non-denaturing gel electrophoresis. Bands were detected by invertase activity staining. Arrows marked I, II and III indicate the mobilities of the corresponding invertase forms secreted by the slime strain.

Fig. 4. Change in electrophoretic mobility (non-denaturing conditions) after Endo $\mathrm{H}$ treatment of invertase forms secreted by the slime strain. Invertase forms were from pool A (see Fig. 2) after (lane A) or before (lane C) Endo H treatment, or from pool D (see Fig. 2) after treatment with Endo H (lane B). The gel was stained for invertase activity.

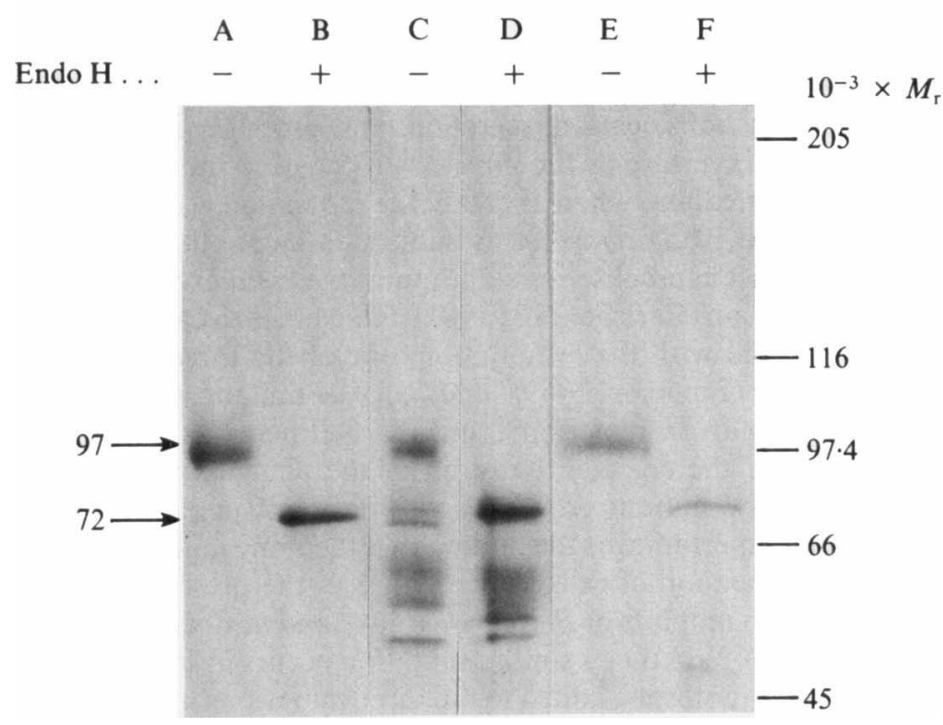

Fig. 5. Polypeptide composition of the three invertase forms secreted by the slime strain. Invertase forms I, II, and III were separated and treated with Endo $\mathrm{H}$ as described in Methods. Electrophoretic analysis was done under denaturing conditions and polypeptides were detected by Coomassie blue staining. Lanes A, C and E, untreated invertase forms I, II and III ; lanes B, D and F, electrophoretic pattern of invertase forms I, II and III after Endo $\mathrm{H}$ treatment.

lanes B and D). The glycosylated invertase polypeptide from the wild-type strain appeared to be more heterogeneous and to have a higher $M_{\mathrm{r}}$ (Fig. $6 b$, lane C) than that from the slime strain (Fig. 6b, lane A). 
(a)

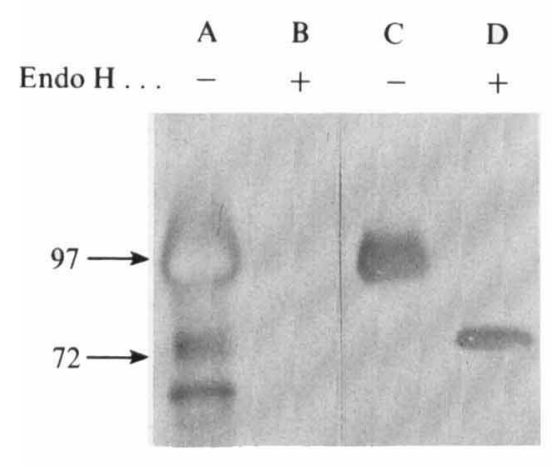

(b)

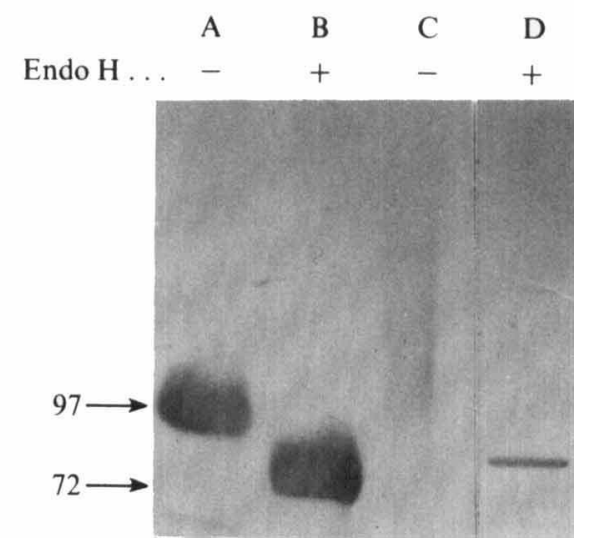

Fig. 6. (a) Samples of slime invertase form I untreated, or treated with Endo $\mathrm{H}$ as indicated, were subjected to SDS-PAGE, transferred to nitrocellulose blotting media and reacted with Concanavalin A (lanes $\mathrm{A}$ and B) or antibodies raised against $S$. cerevisiae invertase (lanes $\mathrm{C}$ and D). (b) Reactivity towards anti-S. cerevisiae invertase antibodies (immunoblotting) of slime invertase form I (lanes A and $\mathrm{B}$ ), and invertase (untreated, or treated with Endo $\mathrm{H}$ as indicated) released by Zymolyase from the cell wall of the wild-type strain (lanes C and D).

\section{DISCUSSION}

We confirmed that invertase is secreted by the slime strain of $N$. crassa as originally reported by Bigger et al. (1972), but we found that secretion occurred continuously without the lag phase described by these authors. Complete inhibition of invertase biosynthesis and secretion by cycloheximide demonstrated that the secreted enzyme is synthesized de novo, whereas inhibition of invertase biosynthesis by tunicamycin is evidence of the importance of the carbohydrate moiety of the enzyme for its translocation, secretion, and probably its stability.

Synthesis and secretion of invertase by the slime strain occurred independently of the carbon source present in the culture medium, whereas catabolite repression was normal in the wild-type strain. Synthesis of invertase in $S$. cerevisiae is subject to catabolite repression (Carlson \& Botstein, 1982), but there exist catabolite-resistant mutants which exhibit an increased rate of invertase synthesis and secretion (Carlson et al., 1984). Resistance to catabolite repression in the slime strain was not correlated with the os mutation, one of the three mutations necessary to maintain the slime phenotype (Emerson, 1963). Thus, an os- 1 mutant showed normal repression when grown in either normal or hypertonic media. Neither was the lack of control of biosynthesis and secretion of the enzyme the result of the phenotypic loss of the wall, since invertase secretion by the os- 1 mutant growing as a protoplast population was repressed by glucose as normal. Equally important was the finding that the same molecular forms of invertase were detected in the spent medium of cells grown either in the presence or in the absence of glucose. Catabolite repression mutants of $S$. cerevisiae hex 1 and hex 2 are affected in hexokinase PII (Entian \& Frohlich, 1984). Whether a similar mutation occurs in slime strains remains to be determined. Anyhow, this trait must be added to the three mutations known to be harboured by the slime cells (Emerson, 1963). However, it should be mentioned that the absence of catabolite repression of invertase production in the slime strain is not the result of a general phenomenon of alteration in the regulatory mechanisms, since synthesis of exocellular phosphatases is still repressed by phosphate (unpublished observations).

Metzenberg (1964) described the presence of two interconvertible forms of invertase in the periplasmic space of wild-type $N$. crassa: a heavy one $\left(s_{20, \mathrm{~W}}=10 \cdot 3\right)$ and a light one $\left(s_{20, \mathrm{w}}=5 \cdot 2\right)$. He concluded that the larger form was a tetramer of the light form. These data were confirmed by Meachum et al. (1971). In this study we found three interconvertible forms of invertase in the slime strain. Apparent $M_{\mathrm{r}}$ values of the three forms under non-denaturing 
conditions were 76000,132000 and 235000 . Similarly, we found three forms of invertase, albeit with slightly different $M_{\mathrm{r}}$ values, in the periplasmic space, bound to the cell wall, and in the culture medium, of the $N$. crassa wild-type strain. Cell-wall-bound invertase was tightly associated with the glucan microfibrillar network, and was mostly released only after glucan digestion with Zymolyase.

Multimeric forms with a predominance of the octamer have been reported for $S$. cerevisiae invertase (Chu et al., 1983). Interestingly, the monomeric form has no catalytic activity (Chu et al., 1983). This phenomenon, plus the close relationship between invertase from $S$. cerevisiae and $N$. crassa revealed by the cross-reaction of the latter with antibodies raised against the yeast enzyme, prompted us to investigate whether or not the low $M_{\mathrm{r}}$ form with invertase activity from the $N$. crassa slime strain represented the monomeric form of the enzyme. Determination of the $M_{\mathrm{r}}$ of the polypeptide from the three forms of invertase secreted by the slime cells by SDS-PAGE gave a value of 97000 ; the $M_{\mathrm{r}}$ of the deglycosylated polypeptide was 72000 . These values are close enough to the $M_{\mathrm{r}}$ of the light active form III observed under non-denaturing conditions. Regardless of the discrepancies in mobility that are due to the different electrophoretic conditions used in each case (see below), this result suggests that the monomeric form of the enzyme is active. The intermediate (II) form appears to be the dimer and the heaviest one (I) the tetramer. Their respective $M_{\mathrm{r}}$ values would then be 194000 and 388000 respectively. The disparity between these values and those obtained by non-denaturing PAGE is due to the abnormal mobilities of polypeptides under these conditions. The $M_{\mathrm{r}}$ calculated for the monomer differs from the value $(51500)$ described by Meachum et al. (1971) for wild-type $N$. crassa. The dissimilarity may be due to the fact that these authors used centrifugation in the presence of guanidine chloride to determine $M_{\mathrm{r}}$, a method which may be largely dependent on molecular shape.

Treatment of all the invertase forms from the slime strain with Endo $\mathrm{H}$ gave the same polypeptide $\left(M_{\mathrm{r}} 72000\right)$. This polypeptide failed to react with Concanavalin A, an indication that all the carbohydrate was bound to the polypeptide moiety of invertase through $N$-glycosidic bonds. The difference in $M_{\mathrm{r}}$ between the glycosylated and deglycosylated polypeptide was 25000 . Accordingly, the sugar moiety in each invertase subunit represents about $25 \%$ of the $M_{\mathrm{r}}$, a value about twice that reported by Meachum et al. (1971) for invertase from the wild-type strain (14\%). The same $M_{\mathrm{r}}$ was calculated for the deglycosylated polypeptide from wild-type $N$. crassa. This indicates that the invertase from the two $N$. crassa strains contains the same polypeptide, and that differences in the $M_{\mathrm{r}}$ values of the glycosylated polypeptides from different invertase fractions are probably due to the different sizes of the carbohydrate moiety of the molecules. Cross-reaction of $N$. crassa invertase with antibodies directed against the enzyme from $S$. cerevisiae (whose polypeptide moiety is significantly smaller: estimated $M_{\mathrm{r}} 60000$; Trimble \& Maley, 1977) implies conservation of a significant portion of the molecule, and its relationship with the suc2 gene product of the yeast suc family (Carlson \& Botstein, 1983).

This work was partially supported by grants no. 3432-83 of the Comision Asesora de Investigacion Cientifica y Tecnologica (Spain) and 400/85 from COSNET (Subsecretaria de Educacion e Investigacion Tecnologicas, Mexico). J.R.-H. is an Investigador Nacional from Mexico, and was on leave from Instituto de Investigacion en Biologia Experimental, Universidad de Guanajuato, and Centro de Investigacion y Estudios Avanzados from the Instituto Politecnico Nacional, Mexico; his stay in Spain was defrayed through CAICyT (Spain) and CONACYT and COSNET (Mexico).

\section{REFERENCES}

Bartnicki-Garcia, S., Bracker, C. E., Lippman, E. \& Ruiz-Herrera, J. (1984). Chitosomes from the wallless slime mutant of Neurospora crassa. Archives of Microbiology 139, 105-112.

Bigger, C. H. \& Braymer, H. D. (1975). Neurospora crassa invertase. A study of amino acids at the active center. Biochimica et biophysica acta 397, 418-427.
Bigger, C. H., White, M. R. \& Braymer, H. D. (1972). Ultrastructure and invertase secretion of the slime mutant of Neurospora crassa. Journal of General Microbiology 71, 159-166.

BURNETTE, W. N. (1981). "Western blotting": electrophoretic transfer of proteins from sodium dodecyl sulfate-polyacrylamide gels to unmodified nitrocellu- 
lose and radiographic detection with antibody and radioiodinated protein A. Analytical Biochemistry 112, 195-203.

Carlson, M. \& Botstein, D. (1982). Two differentially regulated mRNAs with different $5^{\prime}$ ends encode secreted and intracellular forms of yeast invertase. Cell 28, 145-154.

Carlson, M. \& Botstein, D. (1983). Organization of the suc gene family in Saccharomyces. Molecular and Cellular Biology 3, 351-359.

Carlson, M., Osmond, B. C., Neigeborn, L. \& BotsTEIN, D. (1984). A suppressor of snfl mutations causes constitutive high-level invertase synthesis in yeast. Genetics 107, 19-32.

Chu, F. K., Maley, F. \& TaRentino, A. L. (1981). The use of iodinated lectins for determining the degree of deglycosylation of high-mannose glycoproteins by endo- $\beta$ - $N$-acetylglucosaminidase H. Analytical Biochemistry 116, 152-160.

Chu, F. K., Watorek, W. \& Maley, F. (1983). Factors affecting the oligomeric structure of yeast external invertase. Archives of Biochemistry and Biophysics 233, 543-555.

Chung, P. L. Y. \& Trevithick, J. R. (1970). Biochemical and histochemical localization of invertase in Neurospora crassa during conidial germination and hyphal growth. Journal of Bacteriology 102, 423-429.

EMERSON, E. (1963). slime, a plasmodioid variant of Neurospora crassa. Genetica 34, 162-182.

Esmon, B., Novick, P. \& Schekman, R. (1981). Compartmentalized assembly of oligosaccharides on exported glycoproteins in yeast. Cell 25, 451-460.

ENTIAN, K. D. \& Frohlich, K. U. (1984). Saccharomyces cerevisiae mutants provide evidence of hexokinase PII as a bifunctional enzyme with catalytic and regulatory domains for triggering carbon catabolite repression. Journal of Bacteriology 158, 29-35.

GABRIEL, D. \& WANG, S. F. (1969). Determination of enzymatic activity in polyacrylamide gels. I. Enzymes catalyzing the conversion of nonreducing substrates to reducing products. Analytical Biochemistry 27, 545-554.

Gascon, S. \& LAMPen, J. O. (1968). Purification of the internal invertase of yeast. Journal of Biological Chemistry 243, 1567-1572.

Gascon, S., Neumann, N. P. \& Lampen, J. O. (1968). Comparative study of the properties of the purified internal and external invertase of yeast. Journal of Biological Chemistry 243, 1573-1580.

HAWKES, R. (1982). Identification of Concanavalin Abinding proteins after sodium dodecyl sulphate-gel electrophoresis and protein blotting. Analytical Biochemistry 123, 143-146.

LAEMMLI, U. K. (1970). Cleavage of structural proteins during the assembly of the head of bacteriophage T4. Nature, London 227, 680-685.
Leal-Morales, C. A. \& Ruiz-Herrera, J. (1985). Alterations in the biosynthesis of chitin and glucan in the slime mutant of Neurospora crassa. Experimental Mycology 9, 28-38.

Meachum, Z. D., JR \& Braymer, H. D. (1969). Localization of invertase in the cell wall of Neurospora crassa. Proceedings of the 158th National Meeting of the American Chemical Society, abstract no. 195 .

Meachum, Z. D., JR, Colvin, H. J. \& Braymer, H. D. (1971). Chemical and physical studies of Neurospora crassa invertase. Molecular weight, amino acid and carbohydrate composition, and quaternary structure. Biochemistry 10, 326-332.

MeTZEnBerg, R. L. (1963a). The localization of $\beta$ fructofuranosidase in Neurospora. Biochimica et biophysica acta 77, 455-465.

Metzenberg, R. L. $(1963 b)$. The purification and properties of invertase of Neurospora. Archives of Biochemistry and Biophysics 100, 503-511.

Metzenberg, R. L. (1964). Enzymically active subunits of Neurospora invertase. Biochimica et biophysica acta 89, 291-302.

Millette, C. F. \& ScotT, B. K. (1984). Identification of spermatogenic cell plasma membrane glycoproteins by two-dimensional electrophoresis and lectin blotting. Journal of Cell Science 65, 233-248.

Perlman, D. \& Halvorson, H. O. (1981). Distinct repressible mRNAs from cytoplasmic and secreted yeast invertase are encoded by a single gene. Cell 25, 525-536.

SARgent, M. L. \& WoOdWard, D. O. (1969). Geneenzyme relationships in Neurospora invertase. Journal of Bacteriology 97, 867-872.

SCARBOROUGH, G. A. (1975). Isolation and characterization of Neurospora crassa plasma membranes. Journal of Biological Chemistry 205, 1106-1111.

SelitrenniKofF, C. P. (1979). Chitin synthetase activity from the slime variant of Neurospora crassa. Biochimica et biophysica acta 571, 224-232.

Selitrennikoff, C. P., Lilley, B. L. \& ZuCKer, R. (1981). Formation and regeneration of protoplasts derived from a temperature-sensitive osmotic strain of Neurospora crassa. Experimental Mycology 5, 155161.

Towbin, H., Staehelin, T. \& Gordon, J. (1979). Electrophoretic transfer of proteins from polyacrylamide gels to nitrocellulose sheets: procedure and some applications. Proceedings of the National Academy of Sciences of the United States of America 76, 4350-4354.

Trimble, R. B. \& Maley, F. (1977). Subunit structure of external invertase from Saccharomyces cerevisiae. Journal of Biological Chemistry 252, 4409-4412.

VOGEL, H. J. (1964). Distribution of lysine pathways in fungi: evolutionary implications. American Naturalist 98, 435-466. 